\title{
IMS-LIP-KM: Extension of IMS-LIP Standard for Modeling a New User Profile
}

\author{
Haddani Outman \\ TIMS Team \\ Abdelmalek Essaadi University \\ Faculty of Sciences, Tetouan, \\ Morocco
}

\author{
Amjad Souad \\ TIMS Team \\ Abdelmalek Essaadi University \\ Faculty of Sciences, Tetouan, \\ Morocco
}

\author{
Jellouli Ismail \\ CSSE LAB \\ Abdelmalek Essaadi University \\ Faculty of Sciences, Tetouan \\ Morocco
}

\begin{abstract}
This research presents a solution for modeling the user profile of E-Learners. This solution combines the cognitive and technological sides. It's based on known standards and methods.
\end{abstract}

IMS-LIP standards are extended and adapted so as to build an architecture that better solves problems related to cold start and information overload.

This solution was implemented and the experiment was conducted in order to test how efficient it is. The experiments show results that are satisfying and that outperform similar solutions.

\section{General Terms}

Knowledge management, E-learning, FOAF, IMS-LIP, TBS, MBTI, Felder-Silverman learning style

\section{Keywords}

Knowledge management, E-learning, FOAF, IMS-LIP, TBS, MBTI, Felder-Silverman learning style

\section{INTRODUCTION}

In this work, a collaborative architecture is proposed for an online learning system with extensions compared to existing solutions. These extensions will allow a better adaptation to the learner. Furthermore, it is also taken into account the possibility of applying this solution in a knowledge management context.

Many works have dealt with this question before. Yet, they usually suffer from problems linked to diversity and the mass of information, in addition to having difficulties in ensuring the cold start for the new learners.

This proposal answers to these problems based on two main ideas. First, the user profile is extended by taking into consideration the cognitive side which determines the personality as well as the learning style of the learner. In order to do this, The MBTI tests and the Felder-Silverman questionnaire of learning styles are used respectively.
Secondly, we will build a system inspired by K.M-T.B.S (Knowledge Management - Traces Based System) that collects the activities and behaviors of the user with a view to further exploitation in order to produce recommendations or evaluations to aid decision-making.

We have also modeled the relationships between learners and content objects using the FOAF ontology. This ontology, in addition to its aspect of standard language and the interoperability character it offers, will help us with recommending collaborations between the users.

In the following, the second section will start with the main contribution and shows a general overview of the proposed architecture. The third section will be devoted to the experiment that has been carried out in which the validity of the approach has been proved by empirical measurements. Then, in the forth section, the solution is compared to previous work by highlighting the new contributions and the main features of this solution.

In conclusion, the stock of our work will be taking into account by given some perspectives.

\section{OUR CONTRIBUTION}

This part represents the global architecture of our solution. The description of the user profile is based on the IMS-LIP standard. we extended this standard by adding and updating some elements, as it is shown in "Fig.1".These elements include; a personality type which is the result of the MBTI test, the learning style which is determined by the FelderSilverman questionnaire and the learner activities which are recorded by a TBS system. We have called the new extended profile IMS-LIP-KM.

In this approach, $\mathrm{i}$ is opted to use standard and prove solutions and techniques. This is what guided the choice of IMS-LIP, MBTI, FOAF and Felder-Silverman learning Style..., Using standards ensures interoperability and facilitates the sharing and exploitation of knowledge between different information systems. 


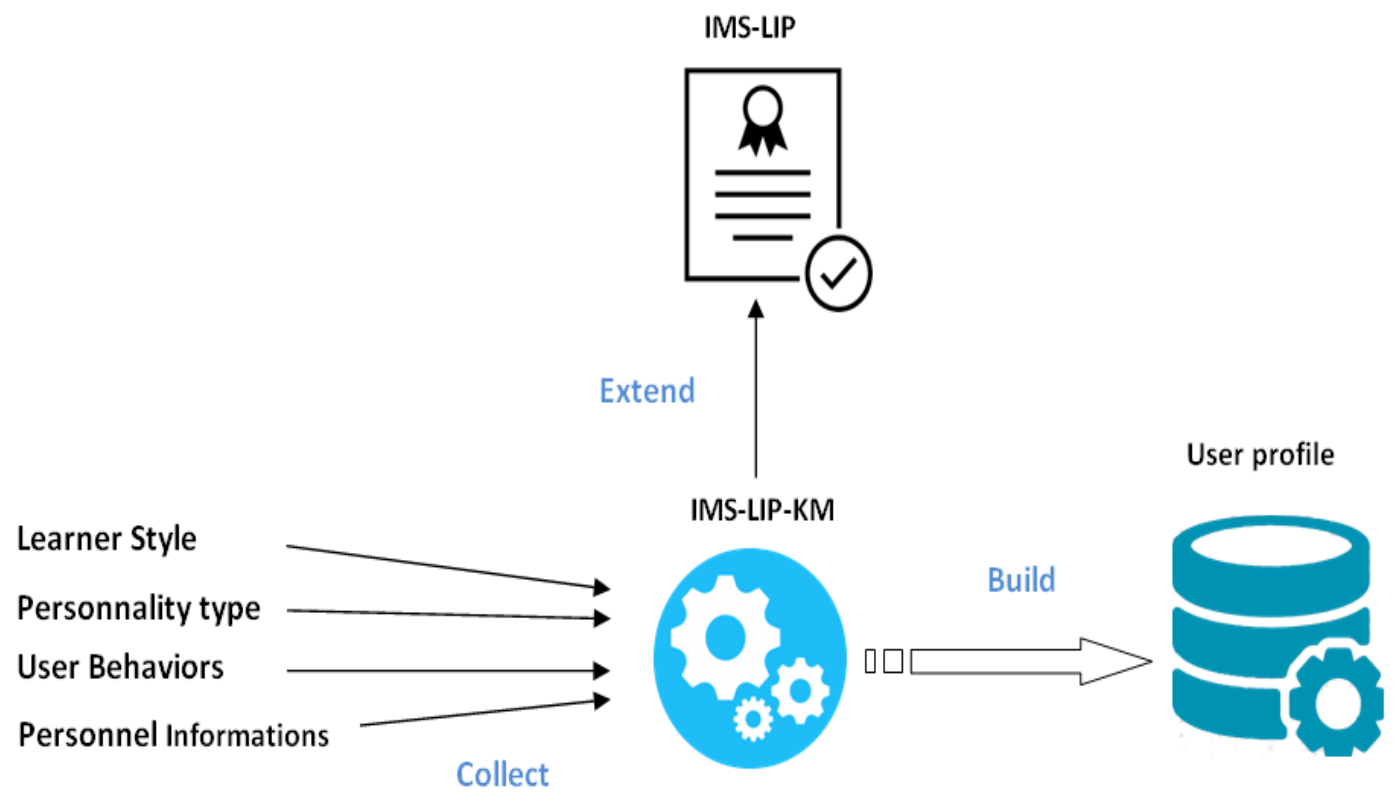

Fig 1 Extension of IMS-LIP

\subsection{The Choice of standard : IMS-LIP vs Papi-Learner}

In the following, a description of two popular standards that describe the profile of the learner is introduced in order to choose the model most convenient to the research.

Several standards are proposed for describing the user profile such as "IMS-LIP" and "PAPI-Learner" (Public and Private Information Learner Specification).

\subsubsection{PAPI Learner:}

PAPI Learner [1] is a standard proposed by the Learner Model Working Group of the IEEE. It specifies the syntax and semantics of a learner model that can be used to characterize a user.

It allows us to have a user model defined according to a standard and therefore keeps it throughout the training and professional life.

The profile is identified by six types of information. In the following "Table 1", we will explain in details the specification of each element:

Table 1 : PAPI-Learner Specification

\begin{tabular}{|c|c|}
\hline Segment & Description \\
\hline Name & $\begin{array}{c}\text { Contains personal information about the } \\
\text { learner which is used mainly by the } \\
\text { administration (name, address, CNSS number, } \\
\text { CIN). }\end{array}$ \\
\hline Relationships & $\begin{array}{c}\text { Contain information about relationships } \\
\text { between the users of the system (classmates, } \\
\text { teachers, employees, managers, etc). }\end{array}$ \\
\hline Security & $\begin{array}{c}\text { Contains security information (password, } \\
\text { private and public keys, ID, authentication } \\
\text { Configuration }\end{array}$ \\
\hline My & $\begin{array}{c}\text { Contains information related to learner } \\
\text { preferences to improve human machine } \\
\text { interactions (useful or unusable I / O, styles }\end{array}$ \\
\hline
\end{tabular}

\begin{tabular}{|c|c|} 
& learning, etc.). \\
\hline Grades & $\begin{array}{c}\text { Contains information about the user's } \\
\text { performance (grades, achievement, rank, etc.) }\end{array}$ \\
\hline Works & $\begin{array}{c}\text { Contain information as an illustration of the } \\
\text { user's capabilities and successes (productions, } \\
\text { jobs, etc.). }\end{array}$ \\
\hline
\end{tabular}

\subsubsection{IMS-LIP (IMS Learner Information}

Package):

IMS Learner Information Package is based on a data model that describes those characteristics of a learner needed for the general purposes of:

- Recording and managing learning-related history, goals, and accomplishments.

- Engaging a learner in a learning experience.

- Discovering learning opportunities for learners.

The specification supports the exchange of learner information among learning management systems (the interoperability), human resource systems, student information systems, enterprise e-learning systems, knowledge management systems, resume repositories, and other systems used in the learning process.

ISSS (Information Society Standardization System was created in mid-1997 by European Committee for Standardization) chose IMSLIP in 2004 as the basis of a European standard for learner data transfer [2].

IMS-LIP consists of eleven elements (called segments). In the following "Table 2", we will clarify in details the specification of each element of the standard.

From the previous description, we can see that the PAPI standard allows to describe the user information while IMSLIP is based on several elements: Activity, Accessibility, goals... which are important for learning experience, goals and for discovering learning opportunities for learners. 
For these reasons, we choose the IMS-LIP standard that we extended and called IMS-LIP-KM as shown in "Table 3". In our proposal, we model the user profile by adapting The Accessibility segment and adding a new Segment "Behaviors".

Table 2 :IMS-LIP-Specification

\begin{tabular}{|c|c|}
\hline Segment & Description \\
\hline Identification & $\begin{array}{c}\text { contains information that identify an individual } \\
\text { such as their name, address, their biographical and } \\
\text { demographic data }\end{array}$ \\
\hline Goal & $\begin{array}{l}\text { The personal goals of the learner, his aspirations, } \\
\text { his wishes for career, etc. }\end{array}$ \\
\hline$\overline{Q C L}$ & $\begin{array}{l}\text { diplomas and certifications of the learner, issued } \\
\text { by the official authorities. }\end{array}$ \\
\hline Accessibility & $\begin{array}{l}\text { this segment contains information about languages } \\
\text { of the learner, on his possible handicaps and on } \\
\text { his learning preferences. These preferences } \\
\text { include cognitive, physical and technological ones } \\
\text { (a preference for a particular platform) }\end{array}$ \\
\hline Activity & $\begin{array}{c}\text { this segment contains information about } \\
\text { completed activities whether they are finished or } \\
\text { not. These activities can be reported by the learner } \\
\text { himself. }\end{array}$ \\
\hline Competency & $\begin{array}{l}\text { the skills and knowledge that the students have } \\
\text { acquired namely: cognitive, affective or } \\
\text { psychomotor. These skills can be associated with } \\
\text { a job or production. They can also be linked to } \\
\text { other information in the Activity and QCL, i.e. } \\
\text { degrees and certifications. }\end{array}$ \\
\hline Interest & $\begin{array}{l}\text { contains information about the learner's hobbies } \\
\text { and interests. }\end{array}$ \\
\hline Transcript & $\begin{array}{l}\text { this segment aims to provide a summary of } \\
\text { Academic diplomas. This helps different countries } \\
\text { in giving the description data of the diplomas and } \\
\text { certifications of the learner. }\end{array}$ \\
\hline Affiliation & $\begin{array}{l}\text { this segment contains information about } \\
\text { institutions or organizations on which the learner } \\
\text { depends. This can include his home institution, } \\
\text { working groups, etc. }\end{array}$ \\
\hline Security Key & $\begin{array}{l}\text { student information such as passwords or keys of } \\
\text { security. }\end{array}$ \\
\hline Relationship & $\begin{array}{l}\text { The set of relationships between the core } \\
\text { components. The core structures do not have } \\
\text { within them identifiers that link to the core } \\
\text { structures. Instead all of these relationships are } \\
\text { captured in a single core structure thereby making } \\
\text { the links simpler to identify and manage. }\end{array}$ \\
\hline
\end{tabular}

\subsection{IMS-LIP-KM Specification:}

First, for the Accessibility segment, we have adopted the existing element "Preference" and added a new element "Personality type". Second, we have added a new segment "Behaviors" which contains three elements: RelationFoaf, Historical and Feedback "Table 3 and Fig.2". In the Following part, we will explain in details the use and composition of each of these elements.
"Table 3" summarizes the updates and extensions that we applied to IMS-LIP standard.

Table 3 : IMS-LIP Extension

\begin{tabular}{|c|c|c|}
\hline Segment & Element & Action \\
\hline Accessibility & Preference & Adopted \\
\cline { 2 - 3 } & Personnality type & Added \\
\hline Behaviors & RelationFoaf & Added \\
\cline { 2 - 3 } & Historical & Added \\
\cline { 2 - 3 } & Feedback & Added \\
\hline
\end{tabular}

The "Fig.2" represents the different elements composing IMSLIP-KM.

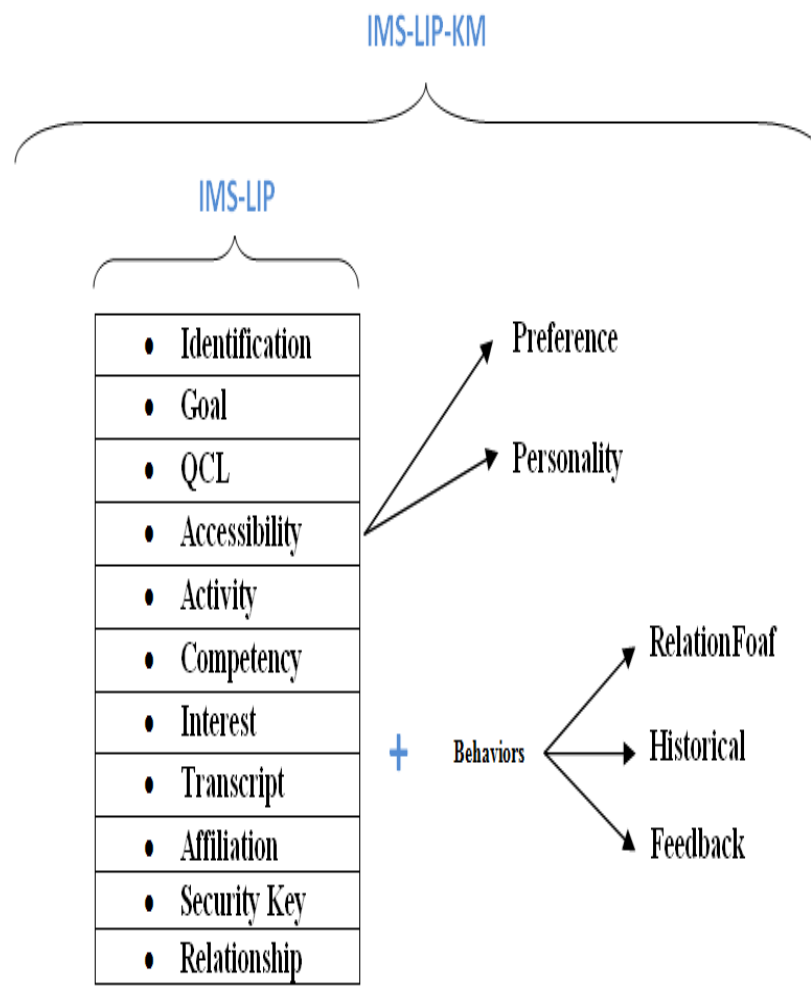

Fig 2 IMS-LIP-KM

We propose in the following a detailed description of different components of our user profile.

\subsubsection{Personality type :}

The personality type is one of the pillars of cognitive psychology that notably dissects the mental mechanisms of information processing. There are several mechanisms to determine or reconcile the personality type of each user.

We have chosen the Myers-Briggs Type Indicator (or MBTI) to discover the type of personality of each user and to introduce a better adaptation of resources by taking the side of cognitive psychology. MBTI is one of the most used personality tests in the world. According to the Washington Post, over two million people are submitted to this test every year as part of their studies and their professional lives. The company that markets it earns about twenty million dollars a year. 
The psychological types of Myers-Briggs Type Indicator (MBTI) are directly inspired by Carl Gustav Jung's theory of psychological types [3], leading to the design of an MBTI indicator. The MBTI is a tool that allows any individual to be aware of his own behavioral preferences. According to this theory, everyone has a natural preference. From an early age, individuals manifest differences in learning styles:

[T] stands for the category who prefers to receive complete and accurate instructions before starting a new task.

[F] stands for the category who prefers to take immediate action and learn on the job.

[J] stands for the category who needs to finish the current subject before moving on to the following.

[P] stands for the category who needs flexibility and exploring possibilities.

[L] stands for the category who needs time and space for completing their task.

Finally, [R] stands for those who are very fast in the assimilation of learning.

This component is modeled in the form of a conceptual vector $\mathrm{Vp}=(\mathrm{Tp}, \mathrm{Fp}, \mathrm{Jp}, \mathrm{Pp}, \mathrm{Lp}, \mathrm{Rp})$, which itself makes it possible to specify the psychological style MBTI of the learner and thus, to inform on these preferences of apprenticeships. There are questionnaires to determine the psychological type of a person. For example, the psychological types of a learner X1 are described as follows: <X1, <Tu, "20\%">, <Fu, "5\%">, $<\mathrm{Ju}$, "35\%">, <Pu, "10\% ">, <Lu," 20\% ">, <Ru," 10\% ">>

In our proposed solution, as mentioned above "table 3", we added a new element "Personality Type", the users are submitted to MBTI test to determinate their personality types. This allows us to solve the cold start problems; users who share the same personality are brought together for support and recommendation.

\subsubsection{Preference : Learning style}

There are several different learning style models in literature such as by [4], Honey and Mumford [5] as well as Felder and Silverman (FSLSM) [6], each proposing different descriptions and classifications of learning types. All these learning style models classify learners in few groups excepting Felder and Silverman that describes the learning style of a learner in more detail, distinguishing between preferences on four dimensions "Fig. 3". Another main issue is that FSLSM is based on tendencies, saying that learners with a high preference for certain behavior can also act sometimes differently. According to Carver [7], "the Felder Model is most appropriate for hypermedia courseware" and it can also be seen, as in "Fig.3", that FSLSM is used very often in research related to learning styles in advanced learning technologies.

FSLSM proposes a questionnaire which is composed of 44 closed questions of two models ( $a$ and $b$ ) that is formed of 4 groups, each one contains 11 questions [8].

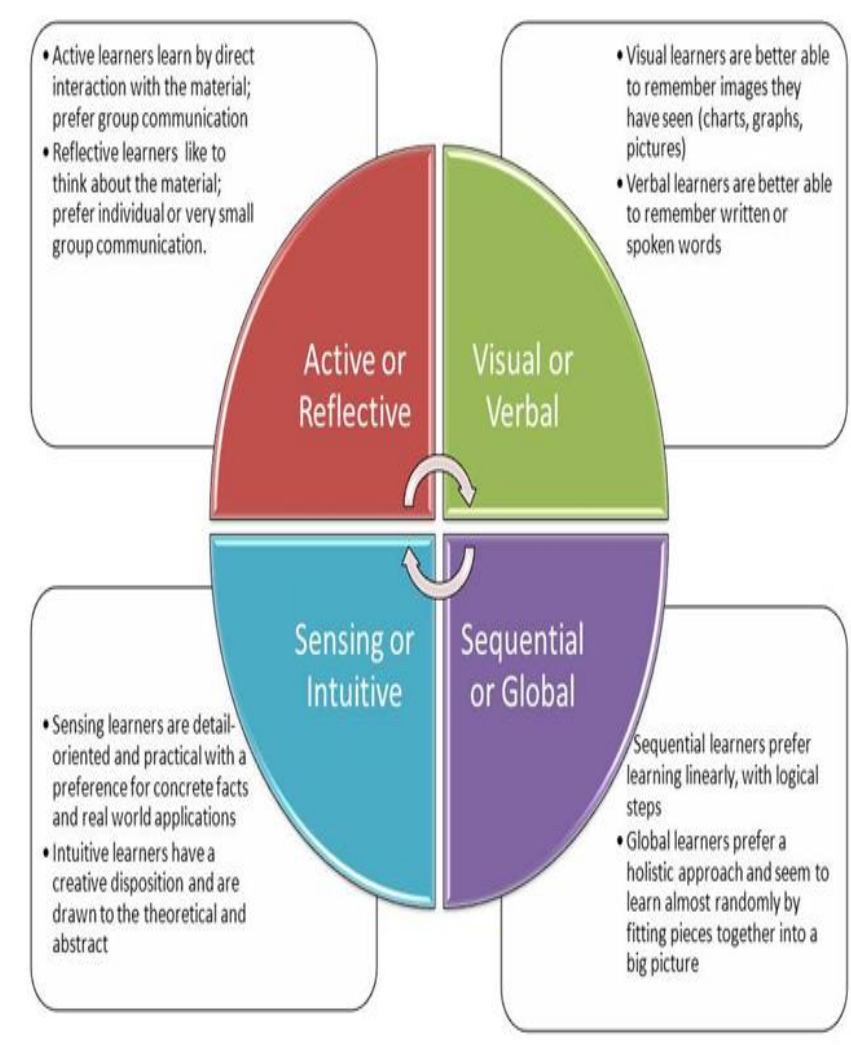

Fig 3 FSLMS

Every group of questions defines the dimension of a student cognitive model which is itself composed of 4 dimensions. Each dimension varies from -11 to 11 with a degree of confidence "Fig.4, Table4" [9].

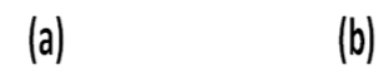

D1: Reflection

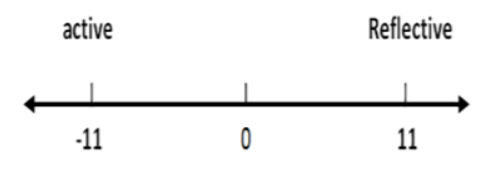

D2: Reasoning

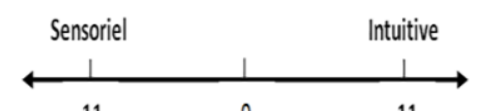

D3: Sensorielle

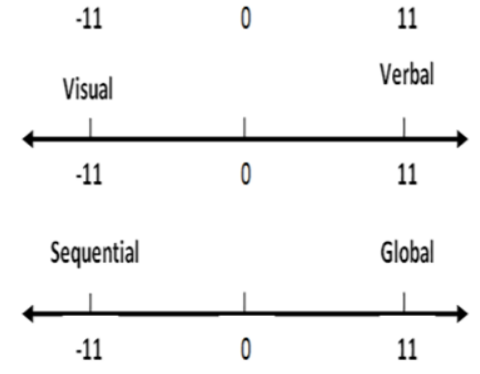

Fig 4 FSLMS : Degree of Confidence

In order to locate the student on these dimensions, we just have to count the number of answers "a" and answers "b" of the 11 corresponding questions and to make the subtraction to obtain a positive number. 
Table 4 : Confidence scale

\begin{tabular}{|c|c|}
\hline Degree of Confidence & Signification \\
\hline $\mathbf{1} 3$ & Incertain \\
\hline $\mathbf{5} 7$ & Moderate \\
\hline $\mathbf{9} 11$ & Strong \\
\hline
\end{tabular}

We have implemented in our Platform a French version of Felder's questionnaire which is translated and adopted by Christophe Piombo.

In our approach, as mentioned above "table 3", we have updated the preference element of the IMS-LIP standard by introducing the Felder-Silverman learning style model. In our framework, after determining users learning styles using FSLSM, we can recommend appropriate resources (Format, order...) for each user in accordance with his style.

\subsubsection{The user's behaviors:}

The problem of tracing users' activities is a field of knowledge management that has brought forth a lot of researches. Some of these researches involve exploiting traces to analyze the activity of a user (or group of users) and understand his behavior. Other works are interested in how to infer and extract information or knowledge for the purpose of assisting the user or personalizing his environment. In general, even if tracing offers good prospects, it is not always easy to take benefit from these traces given the difficulty inherent in their collection, processing and manipulation in a simple and intelligible way.

In our solution the users' Behaviors regroups three important elements: Feedback, Historical and RelationFoaf "Fig.2".

We have built an architecture system called "KM-TBS" for traces processing "Fig. 5 "which was inspired by the research of [10].

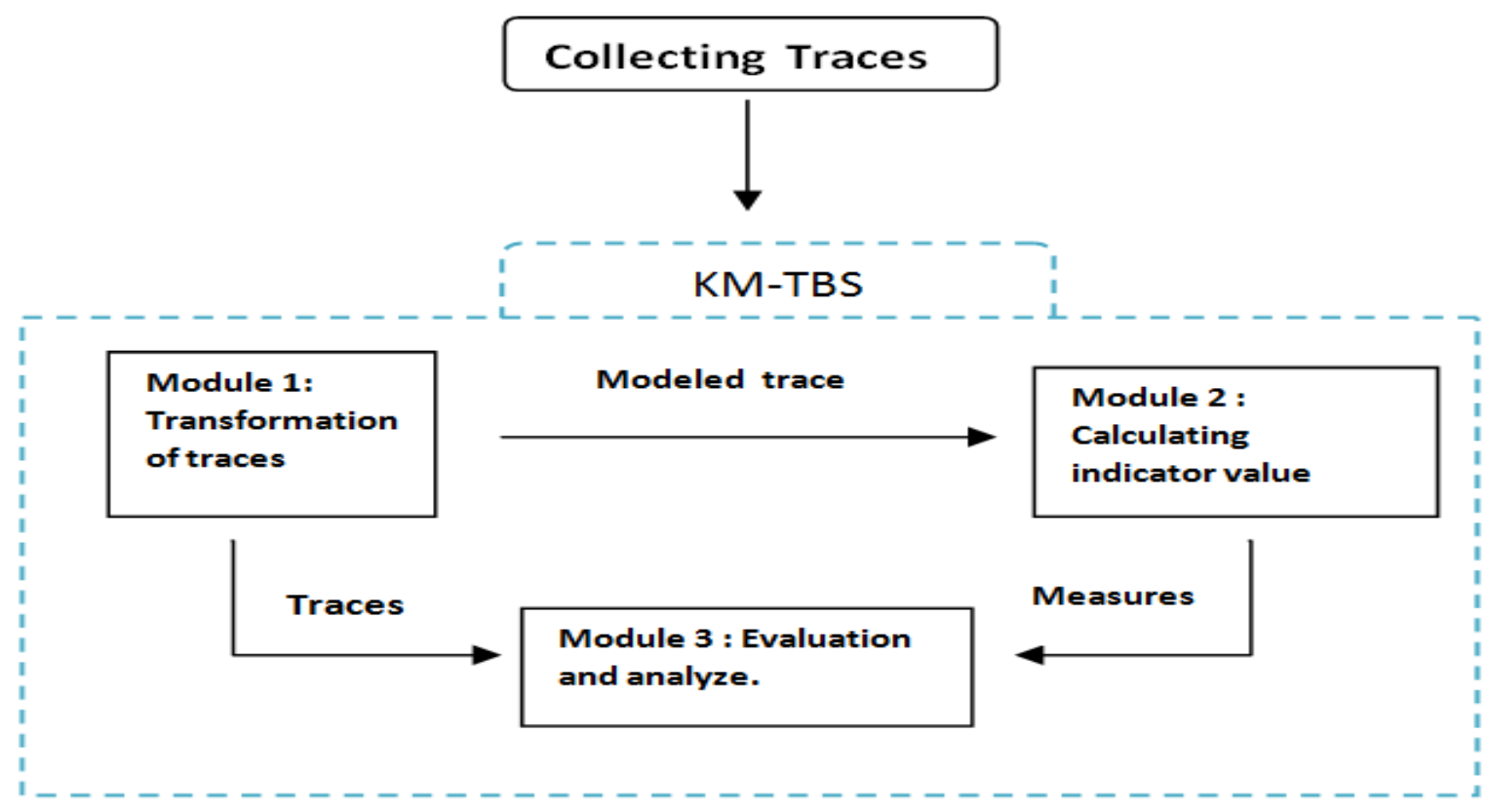

Fig 5 K.M-T.B.S

- Feedback :

Nowadays, Knowledge Management is no longer a process based solely on the transmission of knowledge, but a complex process in which the user is responsible for it by taking an active part to develop knowledge and skills. Thus, by thinking about his learning and the processes he puts in place to achieve his goal, the user becomes at the center of his knowledge.

In this perspective, the system no longer has a transmission role but also an accompanying one. It is in this context that the feedback occurs. This later can be a comment, a participation in the forums, a rating of an article...

\section{* Historical :}

The exploitation of user traces on the system helps to analyze and understand the behavior of each individual, thus facilitating automatic decision-making.

* Relationship :
We used the FOAF ontology to manage this element and to ensure a better exploitation and interpretation of the relations of each individual in the system. FOAF is a linked information system based on the decentralized Semantic Web technology. FOAF is an ontology that describes people, their activities and their relationships with other people and objects.

We have fixed six indicators to analyze the learners' behaviors in our system:

- Number of connections.

- The daily average time of Connection.

- Number of comments.

- Number of pages visited.

- Number of courses completed.

- Number of courses in progress. 
Table 5 :Calculating score

\begin{tabular}{|c|c|c|c|c|c|c|c|c|c|}
\hline $\begin{array}{c}\text { User/ } \\
\text { Indicator }\end{array}$ & $\begin{array}{c}\mathbf{N} \\
\text { Connection }\end{array}$ & $\begin{array}{c}\text { Daily } \\
\text { Time }\end{array}$ & $\begin{array}{c}\mathbf{N} \\
\text { Comment }\end{array}$ & $\begin{array}{c}\text { page } \\
\text { visited }\end{array}$ & $\begin{array}{c}\text { course } \\
\text { completed }\end{array}$ & $\begin{array}{c}\text { cours in } \\
\text { progress }\end{array}$ & $\begin{array}{c}\text { Score } \\
\text { Coffecient } \\
\text { Co }\end{array}$ \\
\hline $\mathbf{1}$ & $1,8667 \%$ & $4,5685 \%$ & $1,6807 \%$ & $5,4313 \%$ & $3,4483 \%$ & $4,7619 \%$ & $3,6262 \%$ & 0,4351 & $\mathrm{C}$ \\
\hline $\mathbf{2}$ & $7,7333 \%$ & $3,0457 \%$ & $0,0000 \%$ & $8,6262 \%$ & $17,2414 \%$ & $14,2857 \%$ & $8,4887 \%$ & 1,0186 & $\mathrm{~B}$ \\
\hline $\mathbf{3}$ & $0,5333 \%$ & $1,2690 \%$ & $0,6303 \%$ & $1,2780 \%$ & $0,0000 \%$ & $0,0000 \%$ & $0,6184 \%$ & 0,0742 & $\mathrm{C}$ \\
\hline $\mathbf{4}$ & $6,1333 \%$ & $2,5381 \%$ & $6,9328 \%$ & $15,6550 \%$ & $24,1379 \%$ & $33,3333 \%$ & $\%$ & 1,7746 & $\mathrm{~B}$ \\
\hline
\end{tabular}

For each indicator, we assign a score by calculating the activity of each user and its relation to the average number of the group. This allows us to determine the final score of the user which is the average result of the six indicators, we will display in "Table 5" an extract of the results of four students.

For example, in order to calculate the forth indicator "Number of page visited", we use the following equation (1) :

$$
\text { i. } \mathcal{P}=\frac{\mathcal{V} . \mathcal{P}}{\sum \mathcal{V} . \mathcal{P}} * 100
$$

Or :

$\mathcal{V} . \mathcal{P}:$ Number of visited pages by this user.

$\sum \mathcal{V} . \mathcal{P}:$ Sum of the visited pages by all users.

After that, our system classifies the learners in three ranks "Table 6" depending on the final score calculated by the six indicators. We calculate this user behavior's rank by the following coefficient "Co", equations (2)(3):

\section{Calculating Score learner "S.L. $\mathcal{L}$ :}

$$
\mathcal{S} \cdot \mathcal{L}=\frac{\sum i}{6}
$$

Or :

$\sum i:$ Sum of the six indicators.

Calculating User Behaviors coefficient "Co":

$$
\mathcal{C O}=\frac{\mathcal{S} \cdot \mathcal{L}}{\sum \mathcal{A} \cdot \mathcal{L}} * 100
$$

Or :

$\mathcal{S} . \mathcal{L}:$ Score learner.

$\sum \mathcal{A}$. $\mathcal{L}$ : Sum of active learners.
Table 6 : Rank and Coefficient

\begin{tabular}{|c|c|}
\hline Coefficient "Co" & Rank \\
\hline Lower than 1 & C \\
\hline Between 1 and 2 & B \\
\hline Greater than 2 & A \\
\hline
\end{tabular}

\section{EXPERIMENTATION}

For the evaluation and the validation of our proposal, we have built an online learning system composed of two platforms "Fig.6". The first Platform is based on Moodle while the second one is our Platform "IMS-LIP-KM" that we have developed with the help of PHP language and Bootstrap library.

To clarify, the first platform allows learners to participate in the educational activity through courses consultation, comments, forums and passing test...

The second platform collects the traces of each learner with the help of the first platform in order to treat them. This treatment produces recommendations and provides the administrator with interesting statistics for analysis and decision support in order to ensure a better adaptation of the educational content.

We have conducted an experimental study for the first year students of Computer Sciences to study the impact of our proposed profile on the learning activity. This course took place in 5 weeks time.

In order to assess its impact, we created two groups of students; each contains 12 people who follow the same educational content. The first group will follow a normal course on Moodle without any intervention or recommendation; while the second benefits from the analysis, adaptations and recommendations offered by our system.

Thanks to our Platform, the administrator of the second group has the opportunity to consult and analyze the educational activity for each learner at any moment. Additionally, he can receive recommendations for decision support and improvement of learning process. In order to do this, several management rules are implemented, such as: 


\section{Moodle Platform

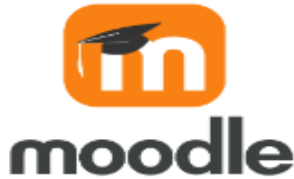

Our Platform

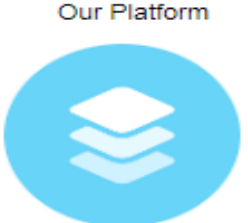

1 Traces treatment 2 Update Users Profil
Learner

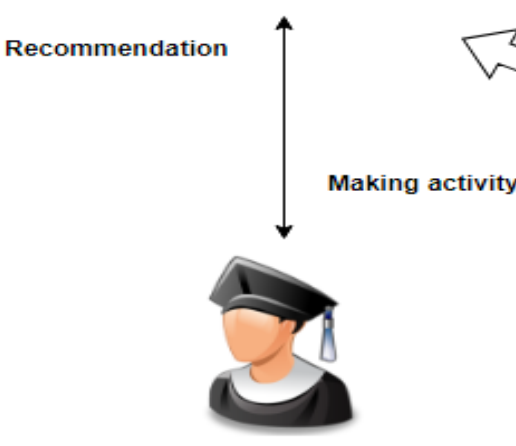

Trace recovery
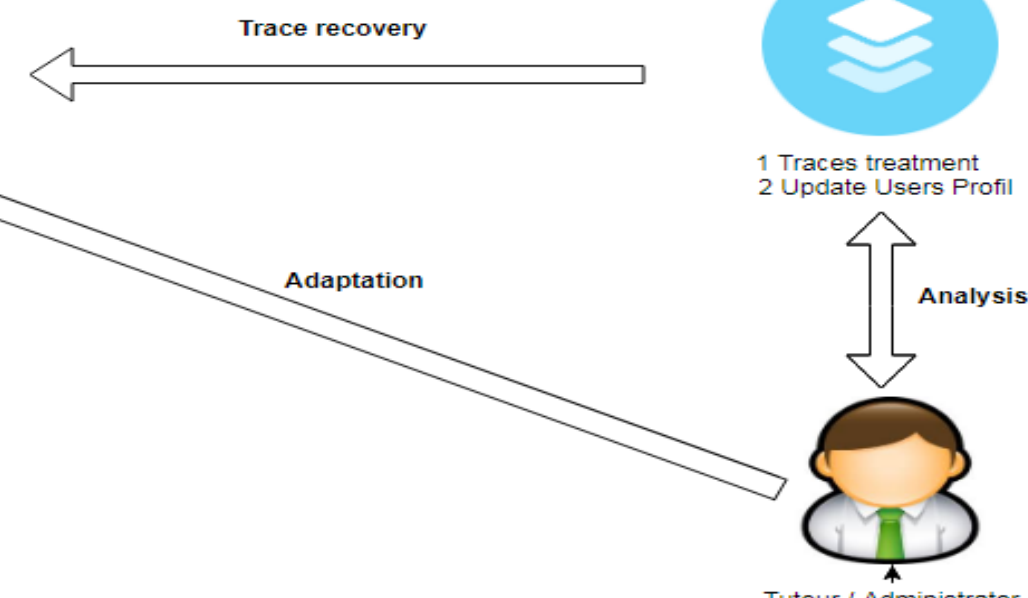

Fig 6 . Our online learning system

If the administrator notices that a new user (Cold start) records bad indicators (ex: number of connection, time remaining in the platform, courses not completed ...) which may be the result of the various problems like: information overload and resistance to automatic recommendation ..., the administrator can recommend to cold start a tutor (a former learner) who shares the same type of personality in order to accompany him.

If the system detects that there is a learner whose indicators are inferior to the average of the group, it will generate recommendations based on the profile information. For instance, the system may recommend the administrator to change the format of the educational content as well as to adopt it according to the learner's preferable style.

If the system detects that there are learners with very similar personality types and that they prefer collective learning, it will recommend that the administrator assign these learners to the same group in order to improve and guarantee a good learning collaboration.

In the following "Fig.7", we present a screenshot of a user profile where we can see several elements namely: Personnel information (Name, Email, Skills, Ranks...), Statistical behaviors, Learning style, Personality type and courses

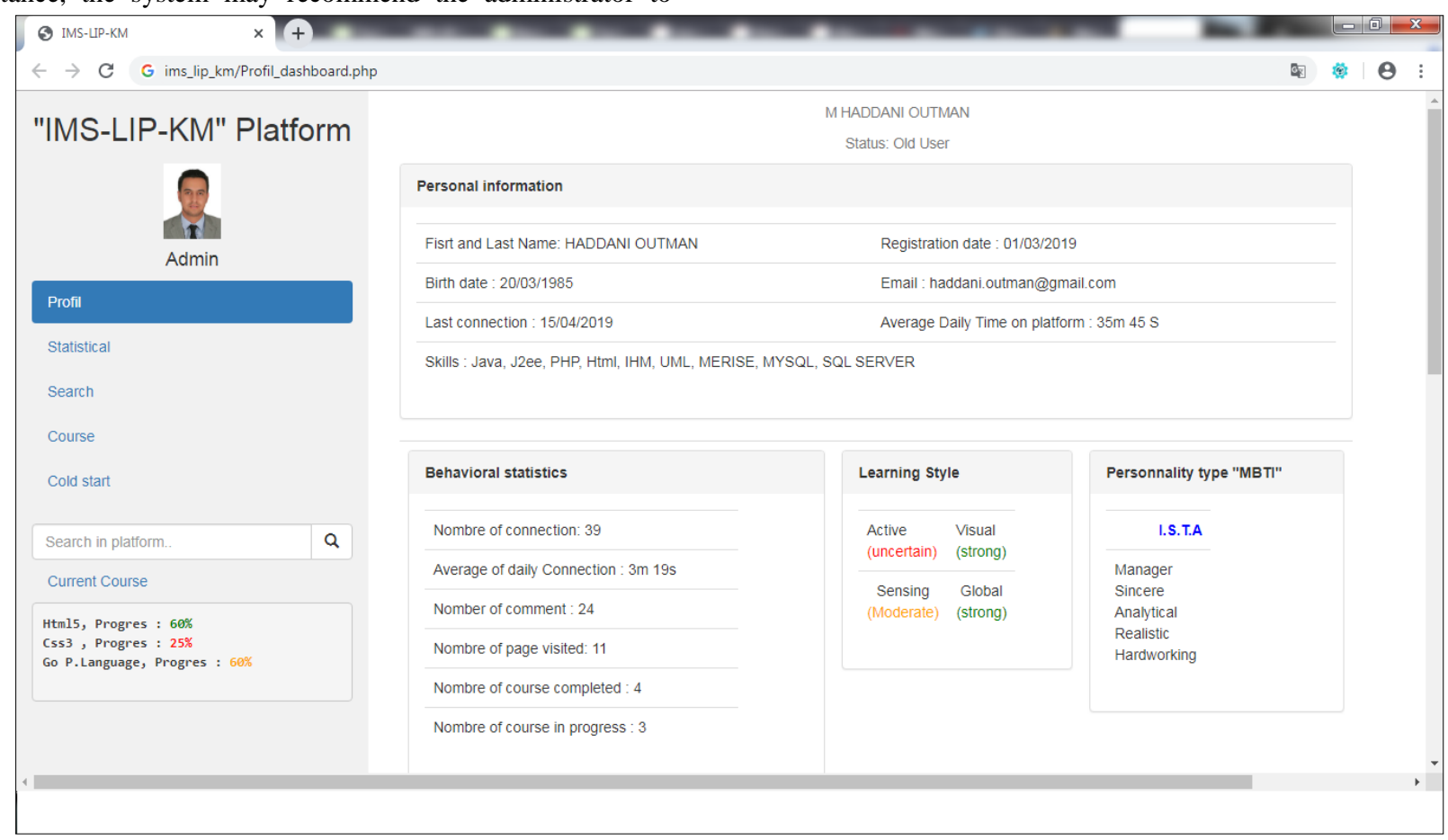

Fig 7. IMS-LIP-KM Profile

In the following "Fig.8", we present a screenshot of a list of users' recommendations which represents the relations between the cold starts and their support (Others users). We can also see several information of these recommendations such as: Subjects, dates, delays and states. 


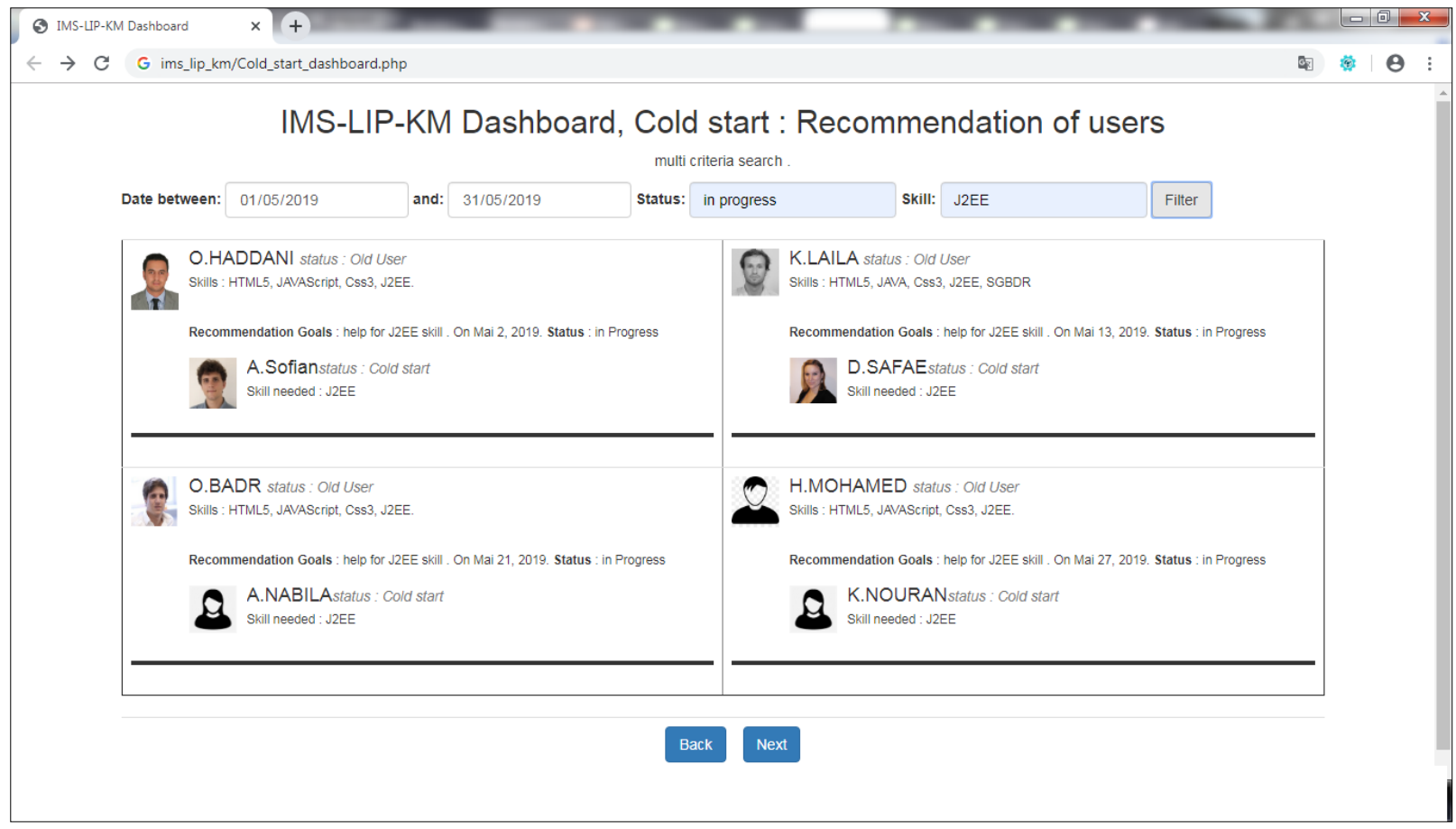

Fig 8. IMS-LIP-KM Cold start Recommendations

We will present in this following screenshot a statistical of learning global activity "Fig.9", which the administrator can easily have a detailed information about Number of connection, pages visited, courses, courses by state, comments and the daily average time of Connection. and In order to facilitate the analyses we also presented those information separated by type of user : Cold starts and others.

\begin{tabular}{|c|c|c|c|c|c|}
\hline \multicolumn{2}{|c|}{ "IMS-LIP-KM" Platform } & \multicolumn{3}{|c|}{ Export $\square$ Excel $\square$ XML } & \\
\hline & & \multicolumn{3}{|l|}{ General Statistic } & \\
\hline \multirow{2}{*}{\multicolumn{2}{|c|}{ Admin }} & Nomber of total connection : 375 & \multicolumn{2}{|c|}{ Nomber of total comment : 1674} & \\
\hline & & Nomber of page visited : 313 & \multicolumn{2}{|c|}{ Average connection time $: 4 \mathrm{~m} 45 \mathrm{~s}$} & \\
\hline & Nombre Total of course : 45 & \multicolumn{2}{|c|}{ Nombre of course Completed:29 } & \\
\hline \multicolumn{2}{|l|}{ Search } & \multicolumn{3}{|l|}{ Nombre of course in progress: 15} & \\
\hline \multicolumn{5}{|l|}{ Course } & \\
\hline \multicolumn{2}{|l|}{ Cold start } & Cold start statistics & Other users statistics & Chart Analysis : Cold start vs others & \\
\hline Search in platform.. & Q & Nombre of connection: 230 & Nombre of connection: 145 & $\nabla$ by Connection nomber & \\
\hline \multicolumn{2}{|l|}{ Current Course } & Daily Connection : $4 \mathrm{~m} 20 \mathrm{~s}$ & Daily Connection : $5 \mathrm{~m} 10 \mathrm{~s}$ & $\begin{array}{l}\square \text { by Comment } \\
\square \text { by Page Visited }\end{array}$ & \\
\hline \multirow{4}{*}{\multicolumn{2}{|c|}{$\begin{array}{l}\text { Htm15, Progres : } 60 \% \\
\text { Css3, Progres : } 25 \% \\
\text { Go P.Language, Progres : } 60 \%\end{array}$}} & Nomber of comment : 673 & Nomber of comment : 1091 & & \\
\hline & & $\begin{array}{l}\text { Nombre of page visited: } \\
113\end{array}$ & $\begin{array}{l}\text { Nombre of page visited: } \\
200\end{array}$ & $\begin{array}{c}\boldsymbol{C}_{\text {start }} \text { old } \\
\text { stat }\end{array}$ & \\
\hline & & Course completed : 12 & Course completed : 17 & & \\
\hline & & Course in progress : 7 & Course in progress : 8 & & . \\
\hline
\end{tabular}

Fig 9.IMS-LIP-KM Statistical

\section{Result analysis:}

From our experimentation, good results are recorded in terms of the overall learning activity. Changes have been observed in all the indicators. What approves our proposal is the cognitive side of learner (personality type, learning style) which also influences the learning activity
In order to analyze our experimentation's result, we have compared the collected indicators of the two groups. Each group indicator represents the average of 12 students. "Fig.10".

The table "Table 7" presents the values of these indicators. 
The first column represents the number of connections of the two groups, which we can see a significant evolution in the number of connection of the Second Group (7.7333) compared to the first group (1.8667). This development subsequently influences the other indicators of the second group, which are also recorded a positive growth (Daily time, number of comment, page visited, course completed, course in progress).

The analysis of this comparison allowed us to identify two main findings. First, the positive impact of our solution on the learning process confirmed by the positive progression of all the indicators of the second group. Second, the evolution of the number of connections on the platform has a positive influence on all educational activity.

The observed Improvement in the indicators of the second group is obtained thanks to the several possibilities that our system offers: recommendations, resource adaptation, statistics, behavior analysis, and the consideration of the individual's cognitive side.

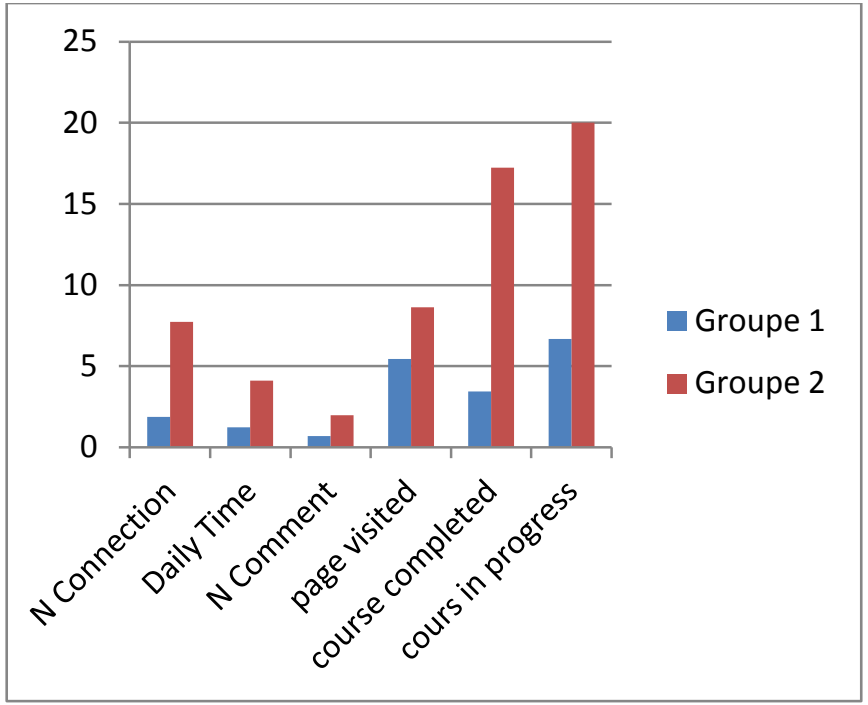

Fig 10. Comparing Indicator of two Groups

Table 7 : indicator values

\begin{tabular}{|c|c|c|c|c|c|c|}
\hline & N Connection & Daily Time & N Comment & page visited & course completed & cours in progress \\
\hline Groupe 1 & 1,8667 & 1,2183 & 0,6803 & 5,4313 & 3,4483 & 6,6667 \\
\hline Groupe 2 & 7,7333 & 4,1117 & 1,9841 & 8,6262 & 17,2414 & 20,0000 \\
\hline
\end{tabular}

\section{RELATED WORKS}

The modeling of a user profile is build on the enumeration of the information necessary for the description of this user. The goal of user profile modeling is to represent, build and then asses information needs in the short, medium and long term. To this end, [11] synthesize in their works the main approaches of representation, construction and evolution of the profile.

a) Profile representation:

There are three types of representation that represent a user profile:

- Ensemblist: the profile is defined by a set of terms or keywords which are possibly weighted.

- Semantic: this type of representation describes things that deal with the meanings of words and sentences.

- Multidimensional: the profile is structured according to a set of dimensions. Each representing a particular aspect (such as personal data, the area of interest).

b) Construction of the profile:

Profile construction process can be explicit or implicit. Explicit construction is based on a collection of information directly provided by the user via the system interface. However, the implicit construction, largely motivated by current work in the field, is based on a method of context inference and user preferences through its behavior when using the system or other everyday applications.

c) Evolution of the profile:

The evolution of the profiles refers to their adaptation to the variation of the interests and information's needs of the user over time [12]. In fact, the evolution of the user profile is often done according to an incremental process based on the addition of new information in the representation of this profile.
Several researches have been carried out in the last years to define the different components of a good profile of user in order to establish a better exploitation of their data. We can find these studies in many domains such as: adaptive hypermedia [13], E-learning [14] , social networks, Knowledge Management systems, big data....

In a previous work [15], we proposed a new collaborative approach for knowledge management based on tacit knowledge of each individuals within a company.

[16]presents a case study on the propagation of buzz in a social network. They consider a user profile as a set of tags provided by the user himself in a social network. Their study shows that the enrichment and building of a dynamic user profile drives the development of buzz.

[17] uses the information and profile of each user as an index to calculate the degree of proximity between users to establish a better recommendation in a folksonomies system.

In the learning area, we find the work of [18] where it shows the importance of using FACEBOOK for the construction of virtual communities in foreign languages to facilitate the exchanges and the development of certain socio-pragmatic skills amongst the learners.

The profile often exists in the field of Data Mining. In the work of [19], an automatic method is presented for extraction of references based on techniques of data mining. The proposed approach consists of two phases: "1" a phase of extraction of all interesting contextual preference rules and "2" a phase of construction of the user profile. At the end of the first phase, there are redundant and superfluous rules while the second phase eliminates superfluous rules in order to have a concise and consistent profile.

Kidneyetal. [20] have identified eight criteria in order to assure a good quality of e-learning course such as: the educational conception, the web development, the edition, 
conviviality and accessibility, maintenance, the author's rights, the content impact.

The work of [21] revealed the scripting approach formed on the case-based reasoning. This approach consists in using educational scenarios that are previously edited and executed in order to help the authors, to reuse previous experiences as well as to adapt them according to their needs and those of the learners.

The main objective from the variety of researches that we have studied is to solve the problems of adapting content to profiles. In this research, the limit of the systems proposed resides in not taking change of the evolution of the user profile. In order words, there is an absence of monitoring as well as the absence of updating the profile in terms of their activities. This causes a lack of interoperability which in term poses difficulties in monitoring user activity histories between various systems. In addition to these problems, our research will also focus on yet another untreated problem which is the lack of essential elements on the cognitive side, such as personality type and preferences.

\section{CONCLUSION}

In this work, a solution for modeling a new user profile called IMS-LIP-KM is presented. This later is the result of the extension of the IMS-LIP standard bearing in mind that this research takes both technological and cognitive sides into consideration. These standards are chosen to ensure integration with different systems including user historical data.

We have used the F.O.A.F ontology for describing the relations between the users and resources, the T.B.S for collecting the user's behaviors, the M.B.T.I for defining the personality type and FSLSM for determining the user preferences.

The experimentations we conducted showed good results and progression for all users of our solution fast in comparison with groups using a state of the art solution.

This system allows to solve cold start related problems of cold start, information overload and ensure a better possible adaptation of the resources to each individual's needs. It can also be adapted for many fields: knowledge Management, Elearning.

Finally, we hope in a forthcoming works experience our solution in a large context with a greater number of users and resources. We also foresee to fully automate the recommendation of supporting users and adapted resources.

\section{REFERENCES}

[1] V Devedzic, J Jovanovic, D Gasevic - " The pragmatics of current e-learning standards" IEEE Internet Computing, 2007 - ieeexplore.ieee.org.

[2] K Keenoy, A Poulovassilis, V Christophides- Conference on Web, Personalisation services for self e-learning networks- 2004 - Springer.

[3] D.T. Willingham, E.H. Hughes, D.G. Doboly, The teachingof Psychology, 42 -2015- 3, p.266-271.

[4] Kolb, D. A..Experiential learning: Experience as the source of learn-ing and development. Englewood Cliffs, -1984-NJ: Prentice-Hall.

[5] Honey, P. [1986]. The Manual of Learning Styles.
Maidenhead, Berks, Peter Honey.

[6] RM Felder, LK Silverman - Engineering education, 1988 - academia.edu.

[7] CA Carver, RA Howard -" Enhancing student learning through hypermedia courseware and incorporation of student learning styles ", 1999 - ieeexplore.ieee.org.

[8] Felder Richard and Silverman Linda [1988]. "Learning and Teaching Styles in Engineering Education". Engr. Education, 78[7], 674-681. 1988.

[9] Piombo Christophe [2007]. Thesis: "Modélisation probabiliste du style d'apprentissage et application à l'adaptation de contenus pédagogiques indexés par une ontologie". October 2007.

[10] SETTOUTI Lotfi. ALL univtlemcen.dz/bitstream/112/873/1/Systeme-a-base-detraces-pour-les-EIAH.pdf.

[11] S Anter, MH El Yazidi, AZellou... - "Towards a generic model of a user profile" 2016 11th International Conference on Intelligent Systems: Theories and Applications [SITA], 2016.

[12] Zemirli W.N., «modele d'acces personnalise a l'information base surlediagrame d'influanceintegrant un profil multidimensionnel», Thése de doctorat, Université

[13] P Brusilovsky" Adaptive educational hypermedia " International PEG Conference, 2001 pdfs.semanticscholar.org.

[14] T Murray - 1999 "Authoring intelligent tutoring systems "- telearn.archives-ouvertes.fr.

[15] O.HADDANI, S.AMJAD . ALL "Personalized recommendation of human resources based on preferences and personality types a collaborative filteringbasedapproach"2016https://ieeexplore.ieee.org/d ocument/7831333.

[16] ManelMezghani, " A Case Study on the Influence of the User Profile Enrichment on Buzz Propagation in Social Media: Experiments on Delicious", 2015- springer.com.

[17] Mohamed Nader Jelassi 1 SadokBenyahia 2 MephuNguifoEngelbert 1, " Étude du profil utilisateur pour la recommandation dans les folksonomies " -2016hal.archives-.

[18] Ahmed moussa, "La construction des communautes virtuelles via facebook et son potentiel en classes des langues: enjeux et prespectives" - 2017 -Jordan journal of modern.

[19] Sandra deAmoa, Mouhamadall , " Contextual preference mining for user profile construction", 2019sciencedirect.com.

[20] [G. Kidney, L. Cummings, AND A. Boehm, "Toward a Quality Assurance Approach to E-Learning Courses“, International Journal on ELearning, 2007,Vol.6, $\mathrm{N}^{\circ} .1 \mathrm{pp}$. 17-30.]

[21] [ H. Seridi and A. Boukehila, " Scénarisation et adaptation des situations d'apprentissage fondée surlaréutilisation de l'expérience", Colloque international sur les TICE. 